\title{
Impact of human mesenchymal stromal cells on antifungal host response against Aspergillus fumigatus
}

\author{
Stanislaw Schmidt ${ }^{1}$, Lars Tramsen ${ }^{1}$, Andreas Schneider ${ }^{1}$, Ralf Schubert ${ }^{2}$, Ada \\ Balan $^{1,3}$, Özer Degistirici ${ }^{4}$, Roland Meisel ${ }^{4}$ and Thomas Lehrnbecher ${ }^{1}$ \\ ${ }^{1}$ Divisions for Pediatric Hematology and Oncology, Hospital for Children and Adolescents, Johann Wolfgang Goethe-University, \\ Frankfurt, Germany \\ ${ }^{2}$ Divisions for Pediatric Pulmonology, Allergology and Cystic Fibrosis, Hospital for Children and Adolescents, Johann Wolfgang \\ Goethe-University, Frankfurt, Germany \\ ${ }^{3}$ Division for "Victor Babes", University of Medicine and Pharmacy, Timisoara, Romania \\ ${ }^{4}$ Division of Pediatric Stem Cell Therapy, Clinic for Pediatric Oncology, Hematology and Clinical Immunology, Medical Faculty, \\ Heinrich-Heine-University, Düsseldorf, Germany
}

Correspondence to: Thomas Lehrnbecher, email: Thomas.Lehrnbecher@kgu.de

Keywords: mesenchymal stromal cells; Aspergillus fumigatus; phagocytosis; hematopoietic stem cell transplantation; immunotherapy

Received: June 09, $2017 \quad$ Accepted: August 03, $2017 \quad$ Published: September 08, 2017

Copyright: Schmidt et al. This is an open-access article distributed under the terms of the Creative Commons Attribution License 3.0 (CC BY 3.0), which permits unrestricted use, distribution, and reproduction in any medium, provided the original author and source are credited.

\section{ABSTRACT}

Mesenchymal stromal cells (MSCs) are increasingly given as immunotherapy to hematopoietic stem cell transplant (HSCT) recipients with refractory graft-versushost disease (GvHD). Whereas the immunosuppressive properties of MSCs seem to be beneficial in GvHD, there is, at the same time, major concern that MSCs increase the risk for infection. We therefore investigated the interplay of human MSCs with Aspergillus fumigatus and the impact of MSCs on different arms of the anti-Aspergillus host response in vitro. Although A. fumigatus hyphae increase mRNA levels of IL6 in MSCs, the extracellular availability of IL-6 and other pro-inflammatory cytokines remains unaffected. Human MSCs are able to phagocyte Aspergillus conidia, but phagocytosis of conidia is not associated with an alteration of the cytokine production by MSCs. In addition, human MSCs do not affect activation and function of $A$. fumigatus specific $\mathrm{CD4}^{+}{ }^{+}$cells, and MSCs do not negatively impact the oxidative burst activity of phagocytes. Our in vitro data indicate that administration of human MSCs is not associated with a negative impact on the host response against $A$. fumigatus and that the fungus does not stimulate MSCs to increase the release of those cytokines which play a central role in the pathophysiology of GvHD.

\section{INTRODUCTION}

Patients undergoing allogeneic hematopoietic stem cell transplantation (HSCT) and suffering from graftversus-host disease (GvHD) are at a significantly increased risk for invasive aspergillosis [1]. Whereas the standard intervention in GvHD consists of immunosuppressive drugs, there is growing interest in cellular therapy with mesenchymal stromal cells (MSCs) in patients refractory to first-line treatment [2]. Mesenchymal stromal cells possess multi-lineage differentiation potential and extensive immunomodulatory properties towards both innate and adaptive immune system by the release of soluble factors including interferons (IFN) and interleukins (IL) $[3,4]$. Although MSCs seem to be a promising strategy in GvHD, their immunosuppressive properties raised concern that MSCs may inadvertently inhibit antimicrobial immune responses, and thus further increase the risk for infection. At the same time, MSCs have specific antimicrobial and pro-inflammatory effects, which 
might aggravate GvHD during an infectious episode [4]. Unfortunately, clinical studies in large and homogenous patient populations on the impact of adoptively transferred MSCs on infectious complications are difficult to perform. We therefore thought to perform in vitro studies evaluating the interplay of MSCs with Aspergillus fumigatus and the impact of MSCs on different arms of the anti-Aspergillus host response.

\section{RESULTS}

\section{Impact of $A$. fumigatus hyphae and conidia on the gene expression and extracellular availability of selected pro- and anti-inflammatory cytokines in human MSCs}

As pro- and anti-inflammatory cytokines such as IFN- $\gamma$, TNF- $\alpha$, GM-CSF, RANTES, IL-17, IL-4, and IL-10 have an important impact on the antifungal host response, as well as cytokines such as IL-6 play a central role in the pathophysiology of GvHD, we assessed the gene expression and extracellular concentration of these molecules in MSCs which were co-incubated with or without $A$. fumigatus conidia and hyphae, respectively [5, $6]$. When co-incubated with $A$. fumigatus conidia, the gene expression of IL6, RANTES and GMCSF in human MSCs was not significantly altered (Figure 1A-1C). Similarly, the concentration of these molecules in the supernatant was comparable in the presence or absence of $A$. fumigatus conidia (Figure 2A-2C).
In contrast, when co-incubated with A. fumigatus hyphae, mRNA levels of IL6 increased in human MSCs by 4-fold as compared to MSCs incubated alone (mean $\mathrm{x}$-fold change \pm SEM, $1.3 \pm 0.7$ vs. $5.3 \pm 0.4, P<0.01$ after 6 hours), whereas the gene expression of RANTES and GMCSF was not affected (Figure 1D-1F). However, the protein levels of all molecules measured in the supernatant after 6 hours decreased by co-incubation with A. fumigatus hyphae compared to MSCs incubated alone, although this decrease did not reach statistical difference (Figure 2D$2 \mathrm{~F}$ ). Levels of mRNA and protein of both IL-17 and the anti-inflammatory cytokines IL-4 and IL-10 were not detectable.

\section{Human MSCs are able to phagocyte $A$. fumigatus conidia}

Co-incubation of $A$. fumigatus conidia with human MSCs resulted in a dose dependent reduction of the formation of fungal colonies (Figure 3A). This effect was not seen when the supernatant of MSCs alone was added to the fungus (data not shown), suggesting that cellular mechanisms play a role in the antifungal activity. When coincubating FITC pre-labeled conidia with MSCs, all conidia were detectable by fluorescence microscopy in both bright field and fluorescein channel, whereas only part of the conidia were detected by calcofluor white staining (Figure 3B), indicating that these conidia were located intracellularly in the MSCs. When adding colchicine and cytochalasin D to block phagocytosis, the effect of MSCs on colony formation was almost completely abrogated (Figure 3C).
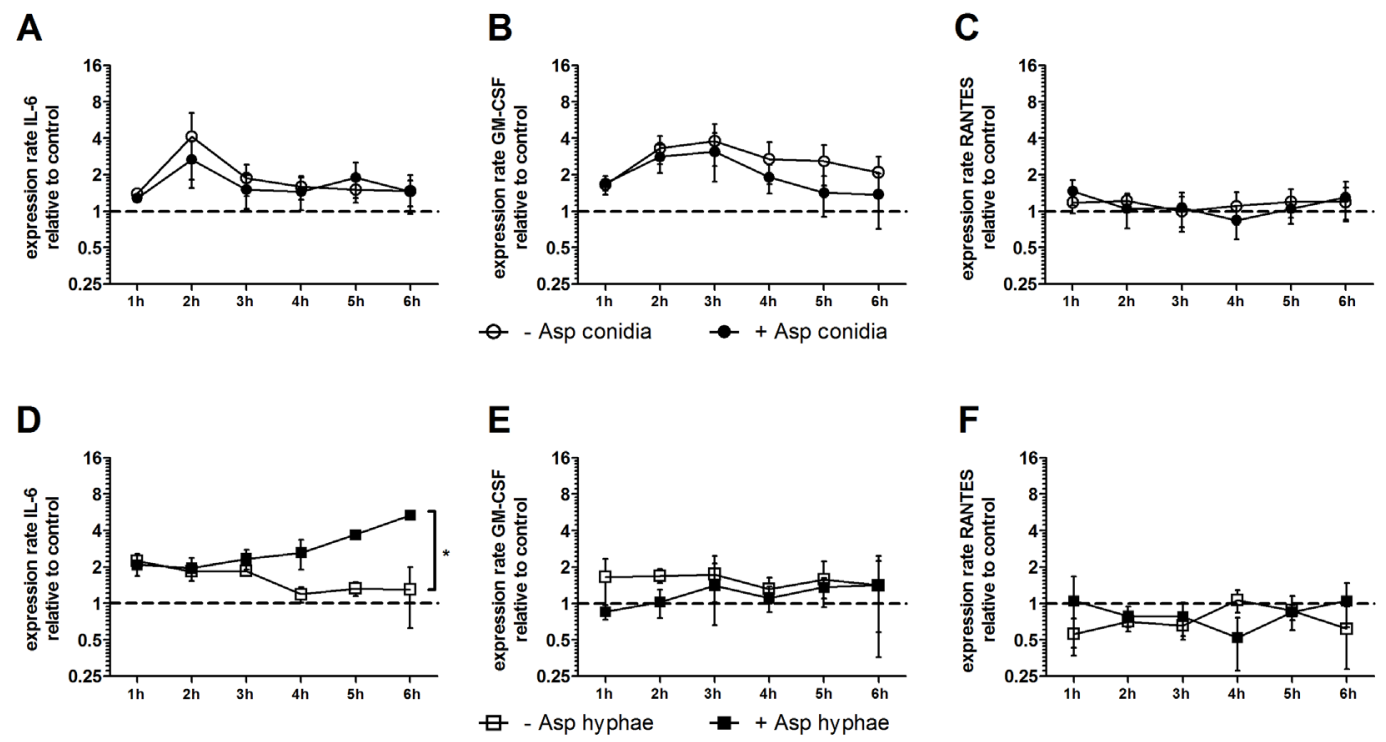

Figure 1: Effect of $A$. fumigatus conidia (A-C) and hyphae (D-F) on the gene expression of IL6, RANTES and GMCSF in mesenchymal stromal cells (MSCs). Gene expression of IL6, RANTES and GMCSF in human MSCs co-incubated with A. fumigatus conidia (filled dots) or A. fumigatus hyphae (filled squares) or incubated alone (open dots/squares). The $\mathrm{X}$ axis represents the time (hours); the first assessment of transcript levels was performed at hour 1 . The $\mathrm{Y}$ axis represents the relative fold-change of gene expression at specific time points to gene expression at time point 0 (dotted line; $<1$ down-regulation, $>1$ up-regulation). Squares and dots represent means, bars the standard error of means (n=3). The $P$ value represents the difference at time point 6 hours. ${ }^{*} P<0.01$ 

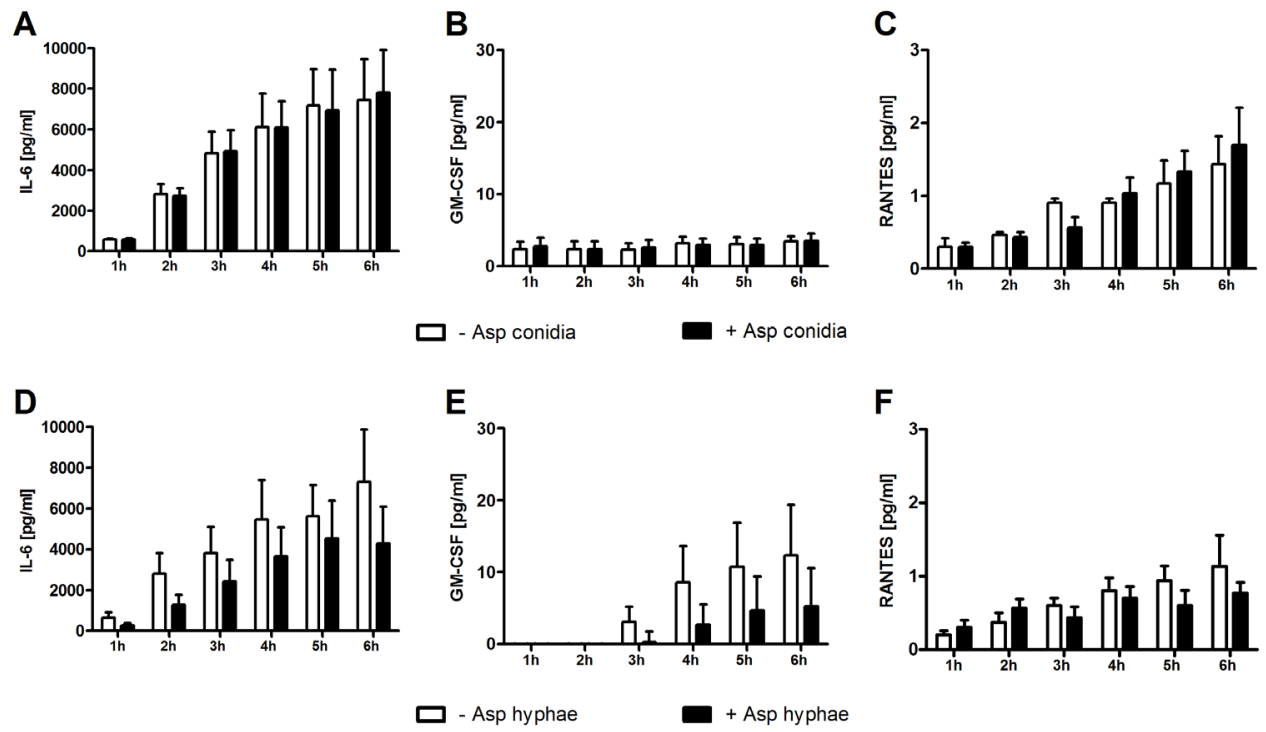

Figure 2: Effect of A. fumigatus conidia (A-C) and hyphae (D-F) on the cytokine concentration in the supernatant of mesenchymal stromal cells. Shown are mean and SEM from three independent experiments.

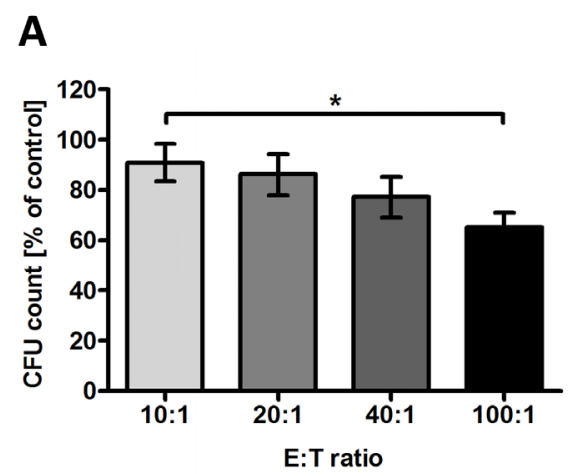

B

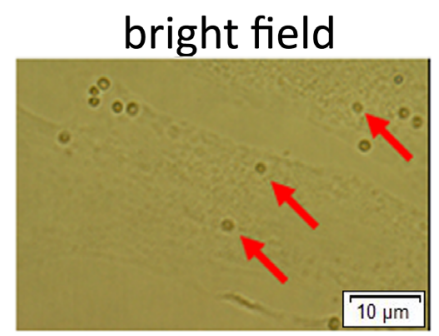

C

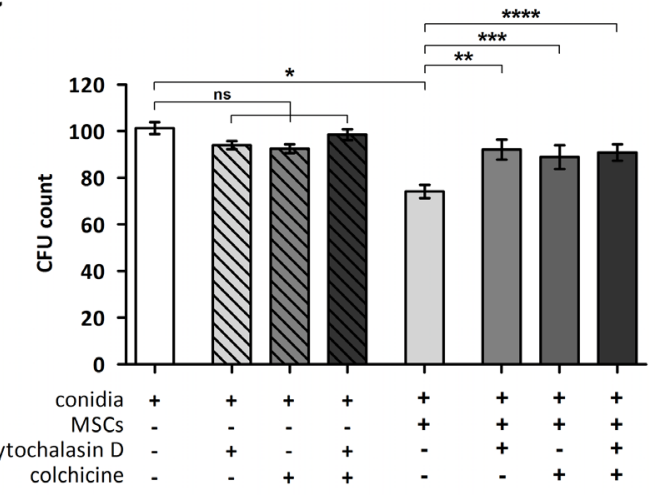

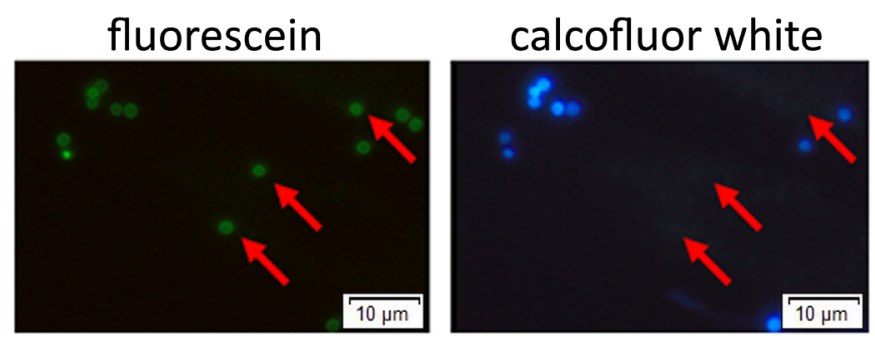

Figure 3: Human mesenchymal stromal cells (MSCs) are able to phagocyte Aspergillus fumigatus conidia. (A) Coincubation of resting conidia of A. fumigatus with human MSCs resulted in a decreased number of colony forming units (CFU) in an effector:target (E:T) ratio dependent manner. Conidia incubated alone served as control (100\%). The bars represent mean, the whiskers SEM of four independent experiments, each of them performed in duplicates; ${ }^{*} P<.05$. (B) FITC-prelabeled A. fumigatus conidia were incubated with human MSCs for $4 \mathrm{~h}$, and calcofluor white staining was performed subsequently. Extracellular located conidia fluoresced with FITC and were also counterstained with calcofluor white, while intracellular conidia (indicated by red arrows) only retained a green signal resulting from FITC pre-labeling. The picture displays one representative experiment out of a total of three experiments (magnification 40x). (C) A. fumigatus conidia were incubated with human MSCs at an E:T ratio of 40:1 for $4 \mathrm{~h}$. Phagocytosis inhibitors cytochalasin $\mathrm{D}(1 \mu \mathrm{mol} / \mathrm{L})$ and colchicine $(2 \mu \mathrm{mol} / \mathrm{L})$ were added to the experiment, individually or in combination. Co-incubation of $A$. fumigatus resting conidia with untreated MSCs significantly reduced the number of CFUs, while the addition of the phagocytosis inhibitors almost completely reversed the effect. Conidia incubated alone served as control. The bars represent mean, the whiskers SEM of three independent experiments, each of them performed in duplicates; ns = not significant, ${ }^{*} P<.0001,{ }^{* * *} P<.005,{ }^{* * *} P<.05,{ }^{* * * *} P<.001$. 


\section{Impact of human MSCs on human anti- Aspergillus $\mathbf{T}$ cells}

As $\mathrm{T}$ cells play a major role in both the pathogenesis of GvHD and the antifungal host response, we investigated whether human MSCs have an impact on activation and function of human anti-Aspergillus $\mathrm{T}$ cells. When coincubating anti-Aspergillus $\mathrm{CD}^{+} \mathrm{T}$ cells with Aspergillus antigens-loaded antigen presenting cells (APCs) or unloaded APCs, the percentage of activated and CD154 expressing T cells as well as the percentage of IFN $-\gamma^{+}$and $\mathrm{TNF}-\alpha^{+}$secreting $\mathrm{T}$ cells among anti-Aspergillus $\mathrm{T}$ cells was higher in the presence of Aspergillus antigens-loaded APCs as compared to unloaded [CD154 (mean \pm SEM, $20.3 \pm 11.9 \%$ vs. $5.6 \pm 3.8 \%), \quad$ IFN $-\gamma \quad($ mean \pm SEM, $14.7 \pm 6.6 \%$ vs. $1.5 \pm 0.5 \%), \quad$ TNF- $\alpha \quad(m e a n \pm$ SEM, $18.9 \pm 7.6 \%$ vs. $1.8 \pm 0.4 \%$ ), Figure 4]. However, no significant effect was observed when MSCs were added to either setting (Figure 4).

When assessing the cytokine levels in the supernatant, adding human MSCs increased the concentrations of IL-6 of anti-Aspergillus T cells incubated with Aspergillus antigens-pulsed APCs (mean \pm SEM, $1488.3 \pm 640.8 \mathrm{pg} / \mathrm{mL}$ vs. $79.8 \pm 48.6 \mathrm{pg} / \mathrm{mL}$ ) as well as of anti-Aspergillus $\mathrm{T}$ cells co-incubated with unloaded APCs alone $(1024 \pm 123.8 \mathrm{pg} / \mathrm{mL}$ vs. $21.4 \pm 8.7 \mathrm{pg} / \mathrm{mL})$. However, IL-6 levels were also increased in the supernatant of antiAspergillus T cells incubated with human MSCs alone as compared to the control (mean \pm SEM, $576.6 \pm 127.7 \mathrm{pg} / \mathrm{mL}$ vs. $4.5 \pm 2.7 \mathrm{pg} / \mathrm{mL}$ ) (Figure 5C). In contrast, adding MSCs to anti-Aspergillus $\mathrm{T}$ cells co-incubated with Aspergillus antigens-loaded APCs did not significantly alter the levels of IFN $-\gamma($ mean \pm SEM, $84.7 \pm 48.4 \mathrm{pg} / \mathrm{mL}$ vs. $85.3 \pm 47.1$ $\mathrm{pg} / \mathrm{mL}$, Figure $5 \mathrm{~A})$, TNF- $\alpha$ (mean \pm SEM, $69.2 \pm 16.2 \mathrm{pg} /$ $\mathrm{mL}$ vs. $90.2 \pm 36.3 \mathrm{pg} / \mathrm{mL}, \mathrm{B}$ ) and GM-CSF (mean \pm SEM, $159.3 \pm 75.9 \mathrm{pg} / \mathrm{mL}$ vs. $138.2 \pm 50.4 \mathrm{pg} / \mathrm{mL}, \mathrm{D})$ in the supernatant. Similarly, comparable concentrations of the respective cytokines in the supernatant were observed when anti-Aspergillus $\mathrm{T}$ cells were co-incubated with unloaded APCs, with human MSCs, or with both unloaded APCs and MSCs, respectively (mean \pm SEM, IFN- $\gamma$ : $12.6 \pm 3.1 \mathrm{pg} / \mathrm{mL}, 6.2 \pm 0.8 \mathrm{pg} / \mathrm{mL}, 10.2 \pm 0.3 \mathrm{pg} / \mathrm{mL}$, Figure 5A; TNF- $\alpha$ : $15.7 \pm 6.2 \mathrm{pg} / \mathrm{mL}, 10.3 \pm 4.7 \mathrm{pg} / \mathrm{mL}, 15.3 \pm 10.7$ $\mathrm{pg} / \mathrm{mL}, 5 \mathrm{~B}$; GM-CSF: $24.4 \pm 3.9 \mathrm{pg} / \mathrm{mL}, 16.7 \pm 4.1 \mathrm{pg} / \mathrm{mL}$, $21.7 \pm 5.4 \mathrm{pg} / \mathrm{mL}, 5 \mathrm{D})$.

No differences were seen in any setting when human MSCs were pre-stimulated with exogenous IFN- $\gamma$ prior to the experiment (data not shown).

\section{Impact of human MSCs on professional phagocytes}

As phagocytes play a major role in the first-line host response against $A$. fumigatus, we investigated the effect of MSCs on the oxidative burst activity of granulocytes. We observed that, as compared to the supernatant of an unstimulated $\mathrm{T}$ cell control, the supernatant of human antiAspergillus T cells co-incubated with Aspergillus antigensloaded APCs increased the oxidative burst activity of granulocytes by $1.5 \pm 0.2$ (mean $\mathrm{x}$-fold change $\pm \mathrm{SEM}$ ) (Figure 6). The increase of the oxidative burst activity of granulocytes was not significantly altered when the

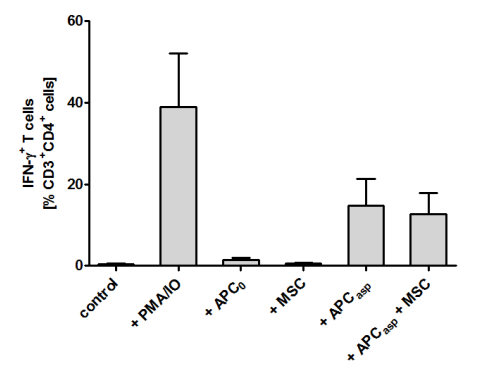

B

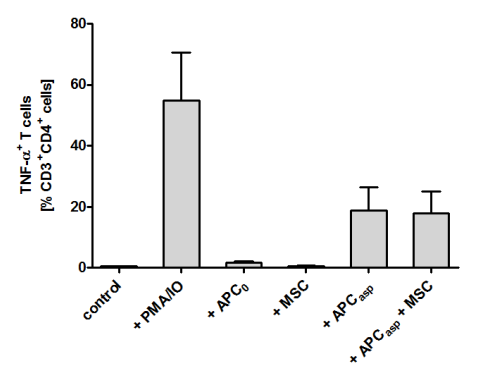

C

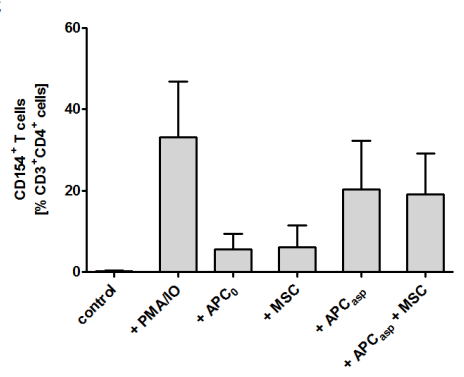

Figure 4: Human mesenchymal stromal cells (MSCs) do not alter the percentage of IFN- $\gamma$ and TNF- $\alpha$ producing and CD154 ${ }^{+}$Aspergillus-specific $\mathbf{T}_{\mathbf{H}} \mathbf{1}$ cells. Unstimulated Aspergillus-specific T cells served as negative, and PMA stimulated T cells as positive control. The bars represent mean, the whiskers SEM of three independent experiments. $\mathrm{APC}_{0}$ unstimulated antigen presenting cell; $\mathrm{APC}_{\mathrm{Asp}}$ A. fumigatus antigen-stimulated antigen presenting cell. 
A

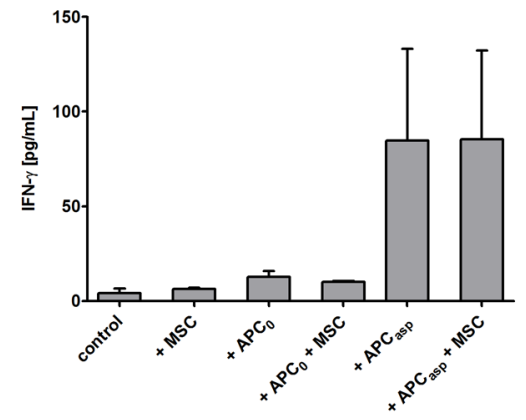

C

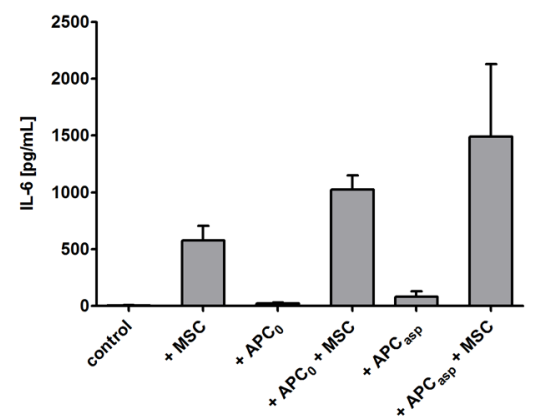

B

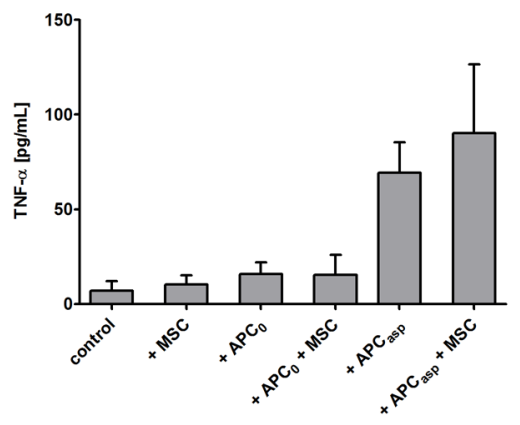

D

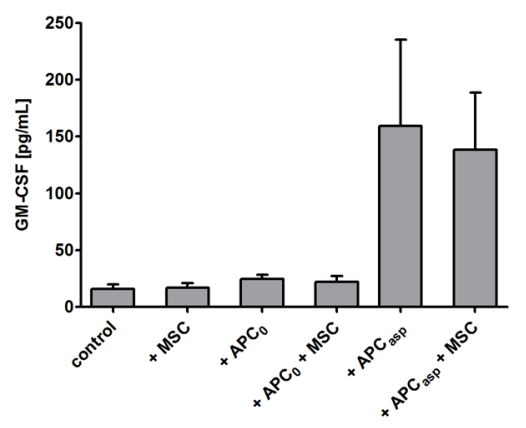

Figure 5: Impact of human mesenchymal stromal cells (MSCs) on the concentration of cytokines in the supernatant of human anti-Aspergillus $\mathbf{T}$ cells. Anti-Aspergillus $\mathrm{CD}^{+} \mathrm{T}$ cells incubated alone served as control. Shown are mean and SEM from three independent experiments. $\mathrm{APC}_{0}$ unstimulated antigen presenting cell; $\mathrm{APC}_{\mathrm{Asp}}$ A. fumigatus antigen-stimulated antigen presenting cell.

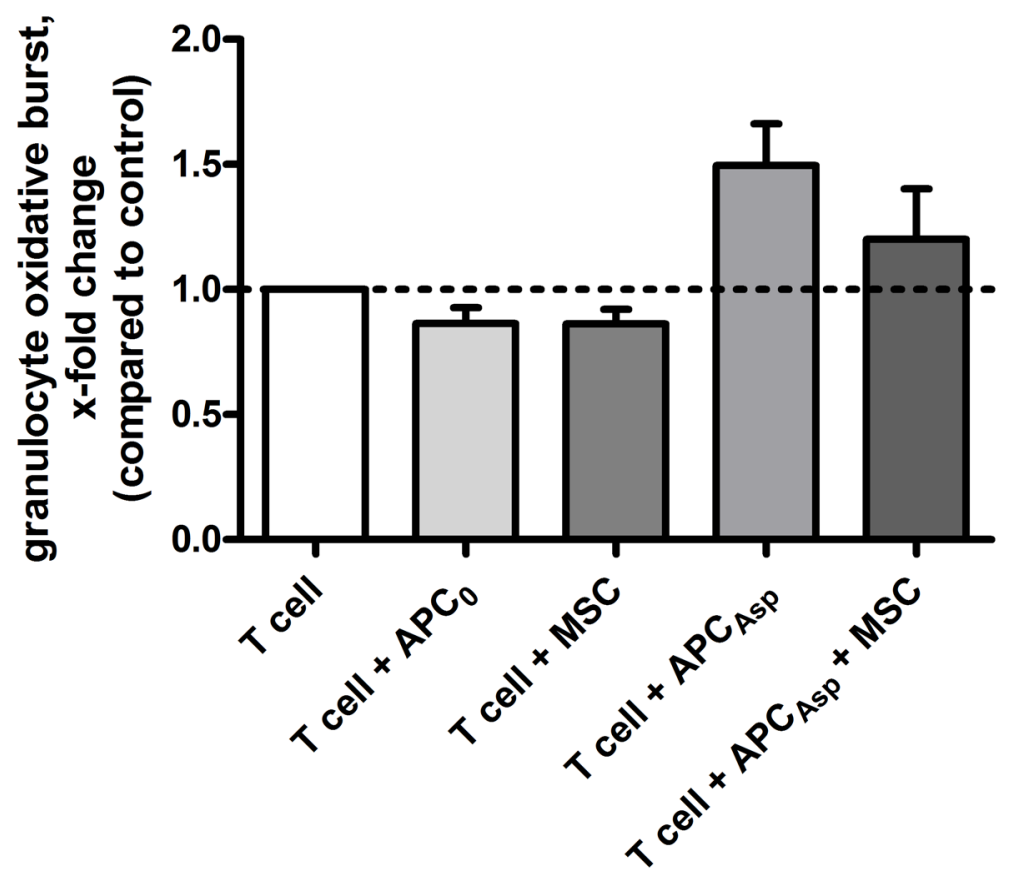

Figure 6: Human mesenchymal stromal cells do not alter the effect of unstimulated or stimulated human antiAspergillus T cells on oxidative burst activity of granulocytes. Shown are mean and SEM of the relative change in oxidative burst activity of granulocytes compared to the activity elicited by the supernatant of unstimulated human anti-Aspergillus $\mathrm{T}$ cells (horizontal dashed line). The results of four independent experiments are shown. $\mathrm{APC}_{0}$ unstimulated antigen presenting cell; $\mathrm{APC}_{\mathrm{Asp}}$ A. fumigatus antigen-stimulated antigen presenting cell. 
supernatant of anti-Aspergillus T cells antigens-loaded APCs co-incubated with human MSCs was used (1.2 \pm 0.2$)$. As compared to the unstimulated $\mathrm{T}$ cell control, a similar oxidative burst activity of granulocytes was seen when using the supernatant of human MSCs alone or of human anti-Aspergillus T cells co-incubated with unloaded APCs

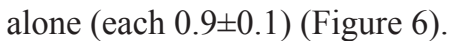

\section{DISCUSSION}

Mesenchymal stromal cells (MSCs) are increasingly administered to patients suffering from GvHD refractory to first-line treatment [2]. However, the immunosuppressive properties of MSCs raised concern whether this strategy further increases the high risk for IFD in this patient population. As no conclusive data of clinical trials are available, and studies with large and homogenous patient populations are difficult to perform, we thought to investigate the interplay of human MSCs and A. fumigatus as well as the effects of human MSCs on the antifungal host response in vitro.

In a first step, we co-incubated $A$. fumigatus hyphae with human MSCs and observed a significantly increased gene expression of IL6 in MSCs, whereas the protein level measured in the supernatant considerably decreased, although this decrease did not reach statistical significance. A similar finding with decreased extracellular availability of the protein despite increased mRNA levels was recently reported for NK cell -derived IFN- $\gamma$, which was due to a decreased release of IFN- $\gamma$ when NK cells were co-incubated with $A$. fumigatus hyphae [7]. In contrast to IL6, co-incubation with $A$. fumigatus hyphae did not significantly alter the gene expression of other proinflammatory molecules such as RANTES and GM-CSF as well as of anti-inflammatory molecules such as IL-4, IL-10, and IL-17A.

In contrast to $A$. fumigatus hyphae, conidia of the fungus did not affect the gene expression and protein release of any of the investigated molecules, corroborating previous results in other immune cells such as $\mathrm{T}$ cells or NK cells, where co-incubation with Aspergillus conidia did not result in any effect. However, our data indicate that human MSCs are able to phagocyte A. fumigatus conidia, which has not described before. As conidia are the resting and not the invasive form of Aspergillus spp., further research needs to evaluate whether this observation reflects a relevant host response mechanism in vivo. To date, data on antifungal properties of MSCs have only been reported in the mouse, where murine MSCs inhibit the growth of Candida albicans directly by IL-17 [8]. This is in contrast to our data observed in human MSCs co-incubated with A. fumigatus, where we did not find relevant levels of IL-17 mRNA and protein, and where the supernatant of MSCs did not exhibit activity against Aspergillus conidia. Unfortunately, due to technical reasons, we were not able to investigate the direct antifungal effect of human MSCs against $A$. fumigatus hyphae.

As human MSCs exhibit important immunoregulatory mechanisms, we investigated the effect of MSCs on important arms of the antifungal host response, such as on anti-Aspergillus $\mathrm{CD}^{+} \mathrm{T}$ cells or on phagocytes. Although neutropenia is the most important single risk factor for invasive aspergillosis, there is a growing body of evidence that also $\mathrm{T}$ cells play a critical role in the antifungal host response. For example, a proof-of principle study demonstrated that the adoptive transfer of anti-Aspergillus $\mathrm{T}$ cells in haploidentical transplant recipients with proven or probable aspergillosis improved the prognosis as compared to patients not receiving antiAspergillus T cells [9]. Our data show that human MSCs do not affect the activation or the functional properties of anti-Aspergillus $\mathrm{CD}^{+} \mathrm{T}$ cells assessed by CD154 or by the production of IFN- $\gamma$ and TNF- $\alpha$. Similar results were observed with unstimulated and IFN- $\gamma$ pre-activated MSCs, both of which are used in the clinical setting for the prevention or treatment of GvHD [10]. In contrast to the levels of IFN- $\gamma$, TNF- $\alpha$, RANTES, and GMCSF in the supernatant, all of which were unaffected by MSCs, adding MSCs to anti-Aspergillus $\mathrm{T}$ cells co-incubated with Aspergillus-antigens loaded APCs increased the concentration of IL-6. As human MSCs incubated alone demonstrated considerably higher IL-6 production than anti-Aspergillus T cells co-incubated with Aspergillus-antigens loaded APCs or with unloaded APCs, respectively, it seems more likely that anti-Aspergillus $\mathrm{T}$ cells enhance the IL-6 production of MSCs rather than MSCs stimulate IL-6 production by anti-Aspergillus T cells. Our findings are in contrast to a recent study which reported that $\mathrm{MSCs}$ reduced the percentage of $\mathrm{CD}^{+}$ and $\mathrm{CD}^{+} \mathrm{T}$ cells producing TNF- $\alpha$, IFN- $\gamma$ and IL- 2 in all functional compartments as well as the amount of cytokines produced [11]. The different observations may be explained by the fact that the authors of this study stimulated the cells with PMA and ionomycin, whereas we used Aspergillus antigens-loaded APCs as they reflect more the in vivo situation. In addition, we employed highly purified cell populations, such as antigen-specific anti-Aspergillus $\mathrm{CD}^{+} \mathrm{T}$ cells, whereas in experiments in which peripheral blood mononuclear cells were used, the presence of other cells such as regulatory $\mathrm{T}$ cells might have a significant impact on the results [12]. In addition, the immunomodulatory effect of MSCs might depend on the developmental stage of the T cell $[10,13]$.

Our data further demonstrate that human MSCs do not impair the oxidative burst activity of neutrophils, which play a crucial role in the early host defense against fungi [14]. Interestingly, in the murine system, MSCstreated macrophages significantly reduced $A$. fumigatus conidia growth as compared to macrophages alone, but the mechanism of this effect remained unclear [15]. 
In conclusion, our data demonstrate that coincubation of human MSCs with A. fumigatus hyphae or conidia do not significantly alter the levels of proinflammatory cytokines in the supernatant. In addition, human MSCs do not affect activation and function of A. fumigatus specific $\mathrm{CD}^{+} \mathrm{T}$ cells, and human MSCs do not negatively impact the oxidative burst activity of phagocytes. The observation that human MSCs are able to phagocyte Aspergillus conidia merits further investigation. Our in vitro data indicate that administration of human MSCs is not associated with a negative impact on the host response against $A$. fumigatus and that the fungus does not stimulate MSCs to increase the release of those cytokines which play a central role in the pathophysiology of GvHD.

\section{MATERIALS AND METHODS}

\section{Aspergillus conidia and hyphae}

Conidia from the Aspergillus fumigatus strain AF4215, which was kindly provided by Cornelia LassFlörl, Innsbruck, Austria, were prepared as previously described [16]. For the generation of hyphae, conidia were plated in 48-well flat-bottom cell culture plates (Nunc, Langenselbold, Germany) and incubated in Yeast Nitrogen Base (Sigma-Aldrich, Taufkirchen, Germany) supplemented with (D)-Glucose (Sigma-Aldrich) at $37^{\circ} \mathrm{C}$ for 17 hours to allow formation of mycelium. For some experiments, conidia were labeled with fluorescein isothiocyanate (FITC)[17] prior to co-incubation with human MSCs. Therefore conidia in $0.1 \mathrm{M}$ carbonate buffer of $\mathrm{pH} 9.0$ were incubated with FITC at a final concentration of $0.1 \mathrm{mg} / \mathrm{mL}$ overnight with rotating at $4{ }^{\circ} \mathrm{C}$. To discriminate between attached and ingested conidia, cells and conidia were washed with phosphate buffered saline (PBS) and stained with calcofluor white (Sigma-Aldrich) as previously described [18].

\section{Mesenchymal stromal cells (MSCs)}

Primary human MSCs of healthy donors were generated and prepared as previously described [19]. At a confluence of $80-90 \%$, MSCs were harvested by adding TrypLE Express (Gibco, Paisley, UK). The cell number was determined by trypan-blue stain in a Neubauerchamber (LO-Laboroptik, Friedrichsdorf, Germany). The study was approved by the Ethics committee (Votum 1830).

\section{Anti-Aspergillus activity of human MSCs}

For assessing the anti-Aspergillus activity, MSCs were incubated in 48-well-plates (Nunc) overnight. After washing, cells were co-incubated with 1000 conidia in $1 \mathrm{~mL}$ medium at different effector:target ratios. After 4 hours, $100 \mu \mathrm{L}$ were spread on a Sabouraud glucose agar plate (Becton Dickinson, Heidelberg Germany) and incubated overnight. The anti-conidial effect was assessed by comparing the average number of colony-forming units (CFUs) with and without co-incubated MSCs, respectively. Cytochalasin D $(1 \mu \mathrm{mol} / \mathrm{L})$ and colchicine $(2 \mu \mathrm{mol} / \mathrm{L})$ (Sigma-Aldrich) were used as phagocytosis inhibitors as described previously [20].

\section{Preparation of RNA and gene expression analysis}

MSCs were co-incubated alone or with Aspergillus conidia or hyphae, respectively, in 48-well flat-bottom cell culture plates (Nunc) for up to 6 hours. At every hour beginning at hour 1, MSCs from one well of each setting were lysed and total RNA (RNeasy Plus Mikro Kit, QIAGEN, Hilden, Germany) was extracted. Quantitative real-time PCR (qRT-PCR) was performed with cDNA (High-Capacity RNA-to-cDNA Kit, Invitrogen, Darmstadt, Germany) from total RNA using Taqmanprobes (Universal ProbeLibrary Technology, Roche, Mannheim, Germany) according to the manufacturers' instructions and using iQ5 cycler and software version 2.0 (BioRad, München, Germany). Glyceraldehyde 3-phosphate dehydrogenase (GAPDH) served as reference gene. The gene expression analysis was performed by the $2^{-\Delta \Delta \mathrm{Ct}}$-method [21].

\section{Generation of highly purified human anti- Aspergillus $\mathrm{CD4}^{+} \mathrm{T}$ cells}

Anti-Aspergillus $\mathrm{CD}^{+} \mathrm{T}$ cells were isolated from peripheral blood mononuclear cells (PBMCs) of healthy individuals as previously described [22]. A total of $1 \times 10^{8}$ PBMCs obtained by density-gradient centrifugation (Biochrome, Berlin, Germany) were added at a concentration of $1 \times 10^{7} / \mathrm{mL}$ to cytotoxic T lymphocyte (CTL) medium containing RPMI1640 (Gibco), 100 IU/ $\mathrm{mL}$ penicillin $\mathrm{G}, 100 \mu \mathrm{g} / \mathrm{mL}$ streptomycin (Gibco), and $10 \%$ pooled heat-inactivated human serum and stimulated for $16 \mathrm{~h}$ with $7.5 \mu \mathrm{g} / \mathrm{mL}$ Aspergillus fumigatus cell extract (water soluble cellular extracts of $A$. fumigatus (CBS 144-89) [23]). Activated T cells were isolated using the CD154 MicroBead Kit according to the manufacturer's instructions (Miltenyi Biotec, Bergisch Gladbach, Germany). Enriched cells were then stimulated with 50 IU/ml recombinant human interleukin (rhIL)-2 (Chiron, Ratingen, Germany) every other day for up to 14 days and with $2.5 \times 10^{5}$ irradiated autologous $A$. fumigatus-loaded Antigen-presenting cells (APCs) on days 4, 7 and 10. APCs were obtained by the adherence method and were loaded with the respective antigens $(7.5 \mu \mathrm{g} / \mathrm{mL})$ over night. Thereafter, IFN- $\gamma$-secreting cells were enriched using the IFN- $\gamma$ secretion assay (Miltenyi Biotec) and expanded using a rapid expansion protocol for human $\mathrm{T}$ cells [22]. 
Phenotyping of purified T-cells was performed by an 8-color flow-cytometer (FACS Canto II; BD Biosciences, San Jose, USA). Assessment of intracellular cytokine secretion was performed by means of intracellular cytokine flow cytometry (ICC) as described previously $[22,24]$. Positive controls were performed by stimulation with phorbol 12-myristate 13-acetate (PMA; $0.5 \mu \mathrm{g} / \mathrm{mL}$; Sigma-Aldrich) and ionomycin (1 $\mu \mathrm{g} / \mathrm{mL}$; Sigma-Aldrich).

\section{Assessment of oxidative burst activity}

The effect of anti-Aspergillus $\mathrm{T}$ cells on professional phagocytes such as granulocytes and monocytes was assessed by means of the Bursttest (Phagoburst $\AA$, Orpegen Pharma, Heidelberg, Germany), which was used according to the manufacturer's instructions with some modifications. In brief, $100 \mu \mathrm{L}$ of supernatant of antiAspergillus T cells, which had been pre-incubated with Aspergillus antigens-loaded APCs, with unstimulated APCs, or alone, in the presence or absence of human MSCs, respectively, were added to $100 \mu \mathrm{l}$ fresh blood. As negative and positive controls, culture medium or culture medium supplemented with PMA or fMLP ( $N$-formylmet-leu-phe) was added, respectively. After incubation for $10 \mathrm{~min}$, the fluorogen substrate dihydrorhodamin 123 was added and the turnover of the substrate, indicating the oxidative burst activity of the cells, was analyzed by means of flow cytometry (FACS Canto II, BD Biosciences).

\section{Assessment of protein concentrations}

Pro- and anti-inflammatory cytokines were selected by their reported role in the antifungal host response or in the pathophysiology of GvHD, respectively $[5,6]$. The concentrations of cytokines and soluble molecules were assessed using the cytokine bead array (CBA; BD Biosciences) according to the manufacturer's instructions. The lower limits of detection were $1.4 \mathrm{pg} / \mathrm{mL}$ for IL-4, 2.5 $\mathrm{pg} / \mathrm{mL}$ for IL-6, $0.13 \mathrm{pg} / \mathrm{mL}$ for IL-10, $0.3 \mathrm{pg} / \mathrm{mL}$ for IL$17,0.8 \mathrm{pg} / \mathrm{mL}$ for IFN- $\gamma, 0.2 \mathrm{pg} / \mathrm{mL}$ for GM-CSF, $0.1 \mathrm{pg} /$ $\mathrm{mL}$ for CCL5/RANTES and $0.7 \mathrm{pg} / \mathrm{mL}$ for TNF- $\alpha$.

\section{Microscopy}

The fluorescence microscopy was performed using Olympus IX71 microscope system with Olympus LUCPlanFLN 40x objective, with attached Olympus F-View Soft Imaging System camera using the CellSens acquisition software version 1.3 (all Olympus Corporation, Tokyo, Japan).

\section{Statistical analysis}

Data were analyzed using Graphpad $\AA$ Prism $\AA$ version 5.04 (GraphPad Software Inc., La Jolla, USA). Comparisons between groups were performed by unpaired
Student's t-test. A two-sided $P$ value $<.05$ was considered statistically significant.

\section{Author contribution}

All authors designed the study;S.S., L.T., A.S., A.B., Ö.D. and R.S. performed the experiments; S.S., L.T., A.S., and A.B., and T.L. analyzed the data; S.S., R.M and T.L. supervised the study; S.S., L.T., R.M., and T.L. wrote the manuscript; all authors read and approved the manuscript.

\section{ACKNOWLEDGMENTS}

The authors thank Zyrafete Kuçi and Selim Kuçi from the Division of Stem Cell Transplantation and Immunology, Hospital for Children and Adolescents, Johann Wolfgang Goethe-University, Frankfurt, Germany, for their assistance and helpful discussions.

\section{CONFLICTS OF INTEREST}

The authors declare no conflicts of interest.

\section{FUNDING INFORMATION}

This work was supported by research funding from the Barbara and Wilfried Mohr-Stiftung.

\section{REFERENCES}

1. Fukuda T, Boeckh M, Carter RA, Sandmaier BM, Maris MB, Maloney DG, Martin PJ, Storb RF, Marr KA. Risks and outcomes of invasive fungal infections in recipients of allogeneic hematopoietic stem cell transplants after nonmyeloablative conditioning. Blood. 2003; 102:827-833.

2. Baron F, Storb R. Mesenchymal stromal cells: a new tool against graft-versus-host disease? Biol Blood Marrow Transplant. 2012; 18:822-840.

3. Krampera M. Mesenchymal stromal cell "licensing": a multistep process. Leukemia. 2011; 25:1408-1414.

4. Balan A, Lucchini G, Schmidt S, Schneider A, Tramsen T, Kuçi S, Meisel R, Bader P, Lehrnbecher T. Mesenchymal stromal cells in the antimicrobial host response of hematopoietic stem cell recipients with graft-versus-host disease-friends or foes? Leukemia. 2014; 28:1941-1948.

5. Romani L. Immunity to fungal infections. Nat Rev Immunol. 2011; 11:275-288.

6. Tawara I, Koyama M, Liu C, Toubai T, Thomas D, Evers R, Chockley P, Nieves E, Sun Y, Lowler KP, Malter C, Nishimoto N, Hill GR, et al. Interleukin-6 modulates graftversus-host responses after experimental allogeneic bone marrow transplantation. Clin Cancer Res. 2011; 17:77-88.

7. Schneider A, Blatzer M, Posch W, Schubert R, Lass-Flörl C, Schmidt S, Lehrnbecher T. Aspergillus fumigatus responds 
to natural killer (NK) cells with upregulation of stress related genes and inhibits the immunoregulatory function of NK cells. Oncotarget. 2016; 7:71062-71071. https://doi. org/10.18632/oncotarget.12616.

8. Yang R, Liu Y, Kelk P, Qu C, Akiyama K, Chen C, Atsuta I, Chen W, Zhou Y, Shi S. A subset of IL-17(+) mesenchymal stem cells possesses anti-Candida albicans effect. Cell Res. 2013; 23:107-121.

9. Perruccio K, Tosti A, Burchielli E, Topini F, Ruggeri L, Carotti A, Capanni M, Urbani E, Mancusi A, Aversa F, Martelli MF, Romani L, Velardi A. Transferring functional immune responses to pathogens after haploidentical hematopoietic transplantation. Blood. 2005; 106:4397-4406.

10. Sivanathan KN, Gronthos S, Rojas-Canales D, Thierry B, Coates PT. Interferon-gamma modification of mesenchymal stem cells: Implications of autologous and allogeneic mesenchymal stem cell therapy in allotransplantation. Stem Cell Rev Reports. 2014; 10:351-375.

11. Laranjeira P, Pedrosa M, Pedreiro S, Gomes J, Martinho A, Antunes B, Ribeiro T, Santos F, Trindade H, Paiva A. Effect of human bone marrow mesenchymal stromal cells on cytokine production by peripheral blood naive, memory, and effector T cells. Stem Cell Res Ther. 2015; 6:3.

12. Luz-Crawford $\mathrm{P}$, Kurte M, Bravo-Alegría J, Contreras R, Nova-Lamperti E, Tejedor G, Noël D, Jorgensen C, Figueroa F, Djouad F, Carrión F. Mesenchymal stem cells generate a $\mathrm{CD} 4{ }^{+} \mathrm{CD} 25^{+} \mathrm{Foxp}^{+}$regulatory $\mathrm{T}$ cell population during the differentiation process of Th1 and Th17 cells. Stem Cell Res Ther. 2013; 4:65.

13. Rasmusson I, Ringdén O, Sundberg B, Le Blanc K. Mesenchymal stem cells inhibit the formation of cytotoxic $\mathrm{T}$ lymphocytes, but not activated cytotoxic $\mathrm{T}$ lymphocytes or natural killer cells. Transplantation. 2003; 76:1208-1213.

14. Schmidt S, Tramsen L, Schneider A, Balan A, Lehrnbecher T. Immunotherapeutic strategies against mucormycosis in haematopoietic stem cell transplantation. Mycoses. 2014; 57:8-12.

15. Cho SY, Kwon EY, Choi SM, Lee DG, Park C, Park $\mathrm{SH}$, Yoo JH, Choi JH. Immunomodulatory effect of mesenchymal stem cells on the immune response of macrophages stimulated by Aspergillus fumigatus conidia. Med Mycol. 2016; 54:377-383.
16. Schmidt S, Tramsen L, Hanisch M, Latgé JP, Huenecke S, Koehl U, Lehrnbecher T. Human natural killer cells exhibit direct activity against Aspergillus fumigatus hyphae, but not against resting conidia. J Infect Dis. 2011; 203:430-435.

17. Sturtevant J, Latgé JP. Participation of complement in the phagocytosis of the conidia of Aspergillus fumigatus by human polymorphonuclear cells. J Infect Dis. 1992; 166:580-586.

18. Volling K, Thywissen A, Brakhage AA, Saluz HP. Phagocytosis of melanized Aspergillus conidia by macrophages exerts cytoprotective effects by sustained pi3k/akt signalling. Cell Microbiol. 2011; 13:1130-1148.

19. Meisel R, Heseler K, Nau J, Schmidt SK, Leineweber M, Pudelko S, Wenning J, Zimmermann A, Hengel H, Sinzger C, Degistirici Ö, Sorg RV, Däubener W. Cytomegalovirus infection impairs immunosuppressive and antimicrobial effector functions of human multipotent mesenchymal stromal cells. Mediators Inflamm. 2014; 2014:898630.

20. Voigt J, Hünniger K, Bouzani M, Jacobsen ID, Barz D, Hube B, Löffler J, Kurzai O. Human NK cells act as phagocytes against Candida albicans and mount an inflammatory response which modulates neutrophil antifungal activity. J Infect Dis. 2014; 209:616-626.

21. Livak KJ, Schmittgen TD. Analysis of relative gene expression data using real-time quantitative PCR and. Methods. 2001; 25:402-408.

22. Beck O, Topp MS, Koehl U, Roilides E, Simitsopoulou M, Hanisch M, Sarfati J, Latgé JP, Klingebiel T, Einsele $\mathrm{H}$, Lehrnbecher T. Generation of highly purified and functionally active human TH1 cells against Aspergillus fumigatus. Blood. 2006; 107:2562-2569.

23. Braedel S, Radsak M, Einsele H, Latgé JP, Michan A, Loeffler J, Haddad Z, Grigoleit U, Schild H, Hebart H. Aspergillus fumigatus antigens activate innate immune cells via toll-like receptors 2 and 4. Br J Haematol. 2004; 125:392-399.

24. Tramsen L, Beck O, Schuster FR, Hunfeld KP, Latgé JP, Sarfati J, Röger F, Klingebiel T, Koehl U, Lehrnbecher T. Generation and characterization of anti-Candida T cells as potential immunotherapy in patients with Candida infection after allogeneic hematopoietic stem-cell transplant. J Infect Dis. 2007; 196:485-492. 